\title{
George Sand, The Devil's Pool and Other Stories
}

\section{Rita Severi}

\section{(2) OpenEdition}

\section{Journals}

\section{Edizione digitale}

URL: http://journals.openedition.org/studifrancesi/33441

DOI: 10.4000/studifrancesi.33441

ISSN: 2427-5856

\section{Editore}

Rosenberg \& Sellier

\section{Edizione cartacea}

Data di pubblicazione: 1 décembre 2005

Paginazione: 663

ISSN: 0039-2944

\section{Notizia bibliografica digitale}

Rita Severi, «George Sand, The Devil's Pool and Other Stories», Studi Francesi [Online], 147 (XLX | III) |

2005, online dal 30 novembre 2015, consultato il 18 avril 2021. URL: http://journals.openedition.org/ studifrancesi/33441; DOI: https://doi.org/10.4000/studifrancesi.33441

\section{Questo documento è stato generato automaticamente il 18 avril 2021.}

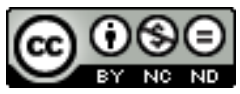

Studi Francesi è distribuita con Licenza Creative Commons Attribuzione - Non commerciale - Non opere derivate 4.0 Internazionale. 


\title{
George Sand, The Devil's Pool and Other Stories
}

\author{
Rita Severi
}

\section{NOTIZIA}

GEORGE SAND, The Devil's Pool and Other Stories, translated by E. H. and A. M. BLACKMORE and Francine GIGUÈRE, Albany, State University of New York, Marilyn Gaddis Rose Editor, «Suny series. Women Writers in Translation», 2004, pp. 228.

1 Poche sono le traduzioni in inglese dei racconti di George Sand e pochissime quelle che includono La Mare au diable, che probabilmente fu tradotto per la prima volta soltanto nel 1895. In seguito furono pubblicate traduzioni dello stesso racconto nel 1911 (edizione Dent, Londra), nel 1917 (New York, P. F. Collier \& Son per la Harvard Classics Shelf), nel 1929 (traduzione di Hamish Miles, 1894-1937), e, ultimamente, l'intero racconto è scaricabile sul sito che propone libri elettronici, gutenberg.org.

Ben venga allora questa raccolta, che oltre al racconto più famoso della produzione sandiana e la Notice ad esso collegata, pubblicata nel 1851, include anche Lavinia (1833), Le Dieu inconnu (1836), La Noce de campagne (1846), breve saggio, scritto prima di La Mare au diable, ma che condivide con il racconto il motivo della danza della morte ed è anche rilevante per la caratterizzazione della vedova Guérin, e, infine, la Lettre à M. Nisard (1836) che presenta riferimenti riconducibili ai primi due racconti. Perciò i curatori di questa raccolta hanno voluto non solo presentare la produzione narrativa della Sand ma anche una breve silloge di quella critica.

Il merito di questa edizione non risiede solo nel fatto di rendere accessibile alcuni tra i migliori scritti brevi di George Sand, ma anche di aver aggiornato le traduzioni seguendo alcuni criteri critici che mettono in luce lo stile originale della scrittrice. A proposito, Jules Lemaître ebbe a dire che la Sand era una scrittrice "facile", nel senso che era scorrevole. Anche Zola ravvisò un fraseggio continuo, un fluire del pensiero, senza intoppi, ma con un ritmo ed una musica del tutto personale. La Sand è innovativa 
quando, disdegnando le costrizioni dell'accademia, decide di scrivere con un linguaggio che corrisponda il più possibile a quello dei suoi personaggi. Non si preoccupa se ogni tanto si verificano degli errori grammaticali, o se il periodo risulta sospeso, perché è attraverso il linguaggio - spesso colloquiale - che i suoi personaggi emergono nella loro vitalità quotidiana. Anche la punteggiatura, nei suoi racconti, tende a differenziare $\mathrm{i}$ personaggi e a introdurre un passo, o una velocità di lettura diverso nelle descrizioni. I curatori hanno notato, per esempio, che la Sand usa la punteggiatura con maggiore discrezione dei suoi contemporanei e nelle loro traduzioni hanno cercato di imitarla. Per ottenere un testo inglese finale che corrispondesse al criterio implicito in ogni traduzione che è quello di "sembrare" autentico, i curatori hanno prestato molta attenzione all'idioletto sandiano, per es., agli anglicismi (in Lavinia), alle espressione bibliche, anacronistiche e regionali (del Berry) di La Mare au diable. È interessante vedere come essi hanno risolto la questione della trasmissione delle espressioni dialettali. Nelle traduzioni precedenti, tutti i passi attinenti a "berrichon", per esempio, venivano tradotti nell'inglese corrente (standard english). In questa traduzione, invece, il dialetto francese viene reso con espressioni tipiche delle comunità rurali anglofone che, a una prima lettura, può sembrare quasi una stonatura, ma poi ci si rende conto che è una scelta coraggiosa che dona al lettore i presupposti per appropriarsi del testo. 